\title{
Learning and training complex coronary surgery
}

\author{
Paul Sergeant, MD, $\mathrm{PhD},{ }^{\mathrm{a}}$ and Jan De Raet, $\mathrm{MD}^{\mathrm{b}}$
}

Feature Editor's Introduction-"Learning on the job, particularly surgery, is relatively disorganized... unpredictable ...time-consuming...costly... and more importantly, patient safety may be jeopardized." So, can we protect patients while training competent cardiac surgeons? Is simulation the answer? It seems like the "Holy Grail" of surgical education; it can be standardized across the world and "gives permission to fail, to do so repeatedly and without consequence."

At our center, we found that it directly improves operative performance and efficiency. Take, for example, aortic valve replacement (AVR). Our AVR simulation curriculum consists of weekly sessions over 5 weeks and progresses through the aspects of the procedure in stepwise fashion following the Thoracic Surgery Directors Association simulation curriculum. ${ }^{2}$ The final 2 sessions are completed on the KindHeart simulator, where each trainee completes 2 AVRs. After each case, the hearts are opened, and the fellows receive critiques on stitch placement and efficiency. This provides a unique ability to review performance and identify areas for improvement. It is clear that operative performance and efficiency substantially improve with the simulation at a pace that far outpaces the traditional approach. Muscle memory and repetition are necessary for consistent progression of surgical skills; simulation provides this opportunity.

In this article, the authors explore the challenges of effective training specific to coronary surgery. They propose several innovations in simulation training with an objective evaluation and graduated complexity of tasks. They systematically address perceived training deficiencies with a detailed and clear paradigm. Although this model may appear cumbersome, it addresses the crucial need of formality in surgical education and standardization of trainees' experiences.

There is no doubt that simulation adds value to surgical education. As a community, we need to embrace and expand innovative applications of technologies to produce efficient,

From ${ }^{\mathrm{a} C a r d i a c}$ Surgery Department, KU Leuven, Leuven, Belgium; and ${ }^{\mathrm{b}} \mathrm{Cardiac}$ Surgery Department, St Jan's Hospital, Brussels, Belgium.

Received for publication Feb 26, 2020; revisions received Feb 26, 2020; accepted for publication May 8, 2020; available ahead of print May 21, 2020.

Address for reprints: Paul Sergeant, MD, PhD, KU Leuven, Reigersweide 16, 3390 Sint Joris Winge, Belgium (E-mail: Paulsergeant133@gmail.com).

JTCVS Techniques 2020;3:240-4

2666-2507

Copyright $@ 2020$ The Authors. Published by Elsevier Inc. on behalf of The American Association for Thoracic Surgery. This is an open access article under the CC BY-NCND license (http://creativecommons.org/licenses/by-nc-nd/4.0/).

https://doi.org/10.1016/j.xjtc.2020.05.012

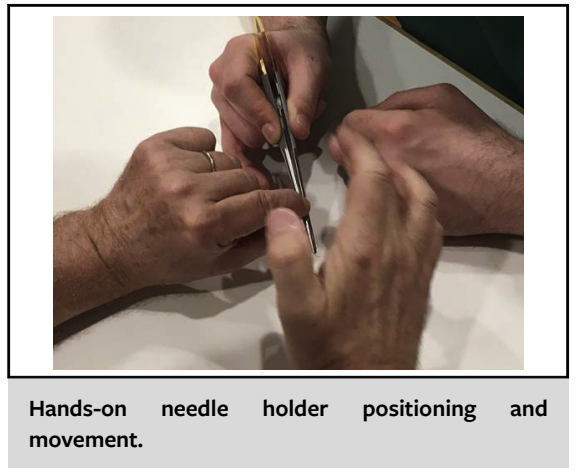

CENTRAL MESSAGE

It is essential for the survival of coronary artery bypass grafting to implement all progress of the science of learning as there are induced learning (conceptual and simulation learning) and operational learning as implemented in other high-risk environments. See Commentaries on pages 245 and 247.

competent, and skilled cardiothoracic surgeons. Our trainees find value in simulation experiences and use these adjuncts to clinical education to accelerate their surgical abilities and enhance their operating performance. This not only allows our trainees to perform more routine procedures earlier, but also facilitates more meaningful participation in more complex operations. We should not settle for "no one ever taught me that"; rather, we should seize the opportunity to standardize surgical education to meet the needs of an increasingly intricate cardiac surgery field.

\section{Maureen Cheung, DO, MS, and Nahush A. Mokadam, MD}

Gaining cardiac surgical competence is a complex, multifactorial process that may take years of experience and on-the-job training. National and international cardiovascular databases have identified that coronary surgery has not adopted such innovations as sequential anastomoses, complete arterial revascularisation, no-touch aorta, off-pump, and other lesser invasive approaches. The only real advances in coronary artery bypass grafting (CABG) over 
the last 50 years have been the grafting of the left internal thoracic artery to the left anterior descending coronary artery and the use of cardioplegic arrest on extracorporeal circulation (ECC). Under certain conditions, the nonimplemented innovations have the potential to reduce early risk and optimize late result. This failure to innovate demands reflection and is not based on the complexity of surgery, since all high-risk and complex working environments have been able to implement innovation. The absence of evidence is also often purported to be the primary cause, but a literature study of the science of learning has identified that many more factors impede or stimulate the implementation of a new technology. Consider the age of the trainee, for example. A younger age can positively influence the formative process, whereas an older age can have both influences. On the one hand, the older surgeon could have an absolute resistance to change, whereas on the other hand, the older surgeon is only too aware of the negative aspects of an existing approach and is willing to adapt irrespective of the "expense."

It is critical to provide suitable educational opportunities to gain the necessary knowledge, judgment, and skills. This editorial focuses on how an optimized induced and organizational learning process can and has been applied in coronary surgery.

\section{SWOT ANALYSIS}

The creation of a SWOT analysis ${ }^{3}$ is a first step toward gaining more in-depth understanding. The major strength of cardiovascular surgical training is the high to very high commitment of the surgical trainee. The major opportunity is clearly the progress made by nonrelated high-risk domains, such as the chemical industry, the military, and the aviation industry, to reduce failure rates to the 5 or 6 $\sigma$ level. This was obtained through strict implementation of the science of learning. Many weaknesses can be identified in the processes as well as in the educational partners. No formal learning processes, objectives, and goals have been identified, except for a minimum number of cases. This minimum number of cases lacks any evidence; since the process, its application, and monitoring are more important than an abstract number of possibly inappropriately performed procedures. In the United States, competence is also confirmed by the program director but is not based on repeated quantitative observations. The technological developments in medical devices and tools have not been mirrored in the training and learning processes. Surgical training has been based on random exposure, not on curricular design. Surgical training has hardly implemented the distant learning and engagement tools available today. Surgical trainers often lack the necessary skills, knowledge of the science of learning, and the commitment to learning. Proficient surgical trainers receive rarely academic or other credit. Finally, scientific and professional organizations have not replaced failing local or regional leadership.

Surgical suites are patient-focused environments, and surgical learning processes should be activated in learnerfocused environments. The consistent time pressure of surgical practice negatively influences the time allocated for training. The patient-surgeon relationship with the existing periprocedural risk and the potential of litigation has understandably impeded training worldwide, leading to loss of attractiveness for the profession.

\section{STRATEGY MAP}

The second step is the strategy map. ${ }^{4}$ Our objective is to provide the best-quality training possible in strictest compliance with the science of learning and with welldefined ethical, financial, stakeholder, and internal perspectives to optimize intangible assets. The financial perspective should be a fair balance between the expenses and the benefits for the trainee and the stakeholders. There are 4 different stakeholders: trainee, patient, society, and colleagues. The trainee wants access, actualized quality of training, application of the science of learning, and social media. The patient wants safe treatment of the highest possible quality. Society similarly wants safe therapy with the highest possible quality, as well as a fair balance between the cost of training and performance. Colleagues expect the highest possible quality of training. The internal perspective forces us to continuously provide and upgrade training services; to leverage and engage the scholars through "select, acquire, and retain"; and, finally, to comply with societal regulations and laws (eg, working hours regulations). The intangible assets that need to be optimized are the human capital, information technology with mobile adaptive and participative environments, and the organizational capital.

\section{SCIENCE OF LEARNING AND TRAINING}

Traditional classroom approaches need to be avoided through an in-depth understanding of the management of codified and tacit knowledge and the taxonomy of learning objectives (ie, knowledge, skills, and attitude), theories of adult learning, deconstruction into teachable components, an individualized approach, modes and triggers of knowledge conversion (ie, learning curves), and barriers to and stimulators of learning (Table 1).

Knowledge is the dynamic flow of information, anchored on the commitments and beliefs of the scholar. This information needs to be codified ${ }^{5}$ (eg, words, pictures, video, audio) as much as possible by the expert and is easily transferable. Each medium needs to be optimized. As an example, whatever can be described in words should be so described. An image should be used only when words give an incomplete description. A video similarly should be replaced by a picture, unless the dynamic aspect is 
TABLE 1. Some impeding and stimulating factors toward the implementation of a new technology

\begin{tabular}{ll}
\hline \multicolumn{1}{c}{ Factor } & \multicolumn{1}{c}{ Description } \\
\hline Technological pull & $\begin{array}{c}\text { By patient, health care professional, provider, } \\
\text { purchaser, media, etc }\end{array}$ \\
\hline Technological push & The innovative tool pushes toward its use \\
Financial aspects & $\begin{array}{c}\text { Benefits for the health care professional or health } \\
\text { service provider }\end{array}$ \\
Learning process & $\begin{array}{c}\text { Induced learning (conceptual as well as } \\
\text { qualitative and quantitative OSATS-based } \\
\text { simulation learning), Organizational learning } \\
\text { (early and late patient outcome data-driven } \\
\text { monitoring of the learning process) }\end{array}$ \\
\hline Department & $\begin{array}{c}\text { Chairman, culture, structure, leadership style, } \\
\text { cross-departmental communication and } \\
\text { support, late outcome reporting and analysis, } \\
\text { group member stability, etc }\end{array}$ \\
\hline Health care & Formative capacity, resistance to change, age, \\
professional & self-assessments, motivation, and commitment
\end{tabular}

essential; the duration of these videos should be expressed in seconds and not in minutes (attention span limitation ${ }^{6}$ ). This information need not be provided in an operating theatre or a classroom but should be provided in an appropriate environment. Examples are our free application, CABG-OPCAB surgery training (in English, Russian, Mandarin, and Portuguese) with close to 2000 scholars worldwide. Education 3.0 goes one step further and entails a confluence of neuroscience, cognitive psychology, and education technology, using web-based digital and mobile technology, including apps, hardware, and software.

The residual noncodified part, tacit knowledge, ${ }^{7}$ is difficult to share and often embedded in group behavior. This demands active presence and interaction with the group. So, knowledge sharing through physical interaction with the trainee should focus on discussing and continuously upgrading the codified knowledge, as well as on sharing the tacit knowledge.

Skills are the psychomotor competencies, gained through sustained practice with expert feedback within a simulated learner-centred environment.

The conceptual learning ${ }^{8}$ process introduces these competencies and deconstructs the procedure in teachable components and each component again in subcomponents. In this way, a curriculum is created. As an example, incision of a coronary vessel and shunt insertion is described in 32 components, including the mandatory 2-way interactions between the surgeon and the anesthesiologist (eg, permission to incise the vessel, shunt positioning). Each skill is described in detail and learned in a low-cost, low-fidelity simulating environment.
This simulation learning process should be monitored by the expert and evaluated using quantitative and qualitative formative tools. A qualitative tool provides rich descriptions of the positive and negative aspects of the performance. A quantitative tool is a numerical assessment, preferably OSATS (Objective Structured Assessment of Technical Skill)-based. We prefer, and have used in thousands of anastomoses and procedures, the FANN OSATS ${ }^{9}$ for learning an anastomosis and the PAR OSATS ${ }^{10}$ for the entire $\mathrm{CABG}$ procedure (includes the crew resource management tools). These training processes should be continued in digital distant environments with strict curricula and appropriate online qualitative and quantitative assessments. We created exactly such an online tool and developed appropriate software for anastomotic techniques, as well as aortic root and mitral valve procedures. More than 6000 scholars have been "processed" worldwide in more than 600 live simulation sessions in 60 countries followed by online courses, webinars followed by online courses and pure online courses. The OSATS-based formative tools of the online courses allow for formal debriefing of the surgical trainee at each step.

In CABG, the anastomosis demands an in-depth understanding of the needle holder. The resident is trained using Castroviejo needle holders with round handles and similar lengths and format forceps. Needle length and size, compounds, coating, swage area, and needle body shape are essential components in the skills learning. An 8-0 needle has a needle body size of 150 microns, so when the needle rotates through a vessel wall, the hole size is 150 microns. This wall trauma can be reduced when the wall has memory (healthy wall), but will be unchanged in some situations, such as a diseased wall or with polytetrafluoroethylene. The wall trauma will be often multiplied when the needle holder needs to be unlocked during the needle wall penetration or when the needle holder drifts during the rotation. A 1-mm drift during rotation multiplies the wall trauma by $10-$ fold; therefore, drift reduction on rotation is one of the first training objectives. This is learned through working on body posture; shoulder, elbow, and wrist optimization (pronation, supination, dorsiflexion, and anteflexion are excluded), stabilization of the hand; and control, balancing, and positioning.

Owing to the extremely reduced airspace of $\mathrm{OPCAB}$ lateral wall revascularization, the lateral, superior, and inferior movement of the needle holder becomes impossible or will reduce the visual channel to the anastomosis. In simulation, the resident learns to release the fixed relationship between the needle and needle holder and learns to move the needle in all possible positions in 3-dimensional space just with rotation and forward/backward movement of the needle holder, again first on a horizontal platform and then later on vertical platforms with gradually reduced airspace. 
The next step is the anastomotic method. Most surgeons still use the parachute technique. An in-depth understanding at the microscopical level of the wall trauma concludes that approximating the parachuted components has a "Gigli" cutting effect on the vessel wall and should be avoided. In addition, the considerable reduction of airspace (the space between the anastomotic platform and the "roof") from several meters to 1 or $2 \mathrm{~cm}$ makes the parachute approach impossible. Thus, residents are trained in simulation to perform nonparachuted anastomoses on a horizontal plane and then on a $90^{\circ}$ inclined platform, and then to gradually reduce the airspace from $8 \mathrm{~cm}$ to 2 to $3 \mathrm{~cm}$.

To move from simulation to live surgery, the scholar needs repetitively to obtain the maximum OSATS score possible. Age and years of residency are irrelevant; only training and assessments are important. Some trainees with high formative skills achieve a maximum score within hours even when starting with minimal skills.

The simulation training is then continued with sequential grafting from a horizontal to a vertical plane with reduced airspace. In accordance to the strategy map, the grafts used have been selected based on their formative capacity (allowing quantitative assessment). A human or animal vein/artery is not an acceptable simulation tool from an ethical/legal perspective, and does not provide insight into wall tension, distribution and radial orientation of the sutures, knot-tying technique, and so on. The grafts used are nonbiological, with a cost of $<1$ Euro for up to 10 anastomoses. The actual simulator (Arroyo simulator selected through a Wiki contest ${ }^{11}$ ) costs $<30$ Euros and is manufactured in a protected workshop in the Czech Republic. It can be replaced by a low-cost 3-dimensional cardboard model. These grafts identify failures in the radial orientation of the sutures, inappropriate suture tension, inversion, inappropriate wall tension, inappropriate angulation of the graft versus the host, inappropriate and irregular distances between suture points, and irregular distance from the rims.

We no longer train residents in on-pump venous anastomoses or in proximal anastomoses on the aorta, because complete arterial and nonaortic revascularization has become our institutional norm for more 2 decades. So the first anastomosis performed by the resident will be the left internal mammary artery to the left anterior descending coronary artery in the OPCAB mode. The next complexity is the sequential arterial anastomosis on the anterior wall. Enucleation (elevation and positioning) of the left ventricle is then performed under strict monitoring of intracardiac pressures and visual supervision by the senior surgeon and anesthesiologist. Each procedure is completely debriefed using the PAR OSATS.

Attitude refers to the readiness of the psyche, conscious and unconscious, to act and react in a certain way. Again, this should be learned not on a patient, but in scenario training, ${ }^{12}$ possibly digitally. In this section, the surgical scholar integrates his knowledge and skills in his response to normal and abnormal surgical processes. In the clinical setting, we have implemented attitude assessments and guidance through the crew resource elements of the PAR OSATS: pace, awareness, relations, planning, announce, review, and reflexion. The MY VIRTUAL SURGERY (MVS) project has not yet addressed this aspect. Through a gradual increase in the online interactive possibilities with the MVS engagement communities and MVS extensive experience in distant online simultaneous webinars, online scenario training becomes within reach.

The third step of surgical training is organizational or operational learning. In this process, objective and quantifiable data are used to monitor the resident's surgical progress. An operational learning database (the KU Leuven CS database) records a rich set of continuous patient and surgical variables to allow mathematical correction for variability. The usual scoring systems with a reduced set of nominal variables are insufficiently powerful. Then all possible quantifiable biological, clinical, and electrocardiographic outcome variables are registered over a time frame that covers the early hazard function (3 months). At repeated intervals and with sufficiently large cohorts, multivariate analyses were performed, after exclusion of clinical outliers, to identify possible distinctive behavior. After a review of these cases, appropriate guidance was implemented. $^{13}$

Training another individual in a surgical practice is the second most important privilege of a surgeon, after treating a patient. Today, training demands the use of modern interactive tools and technologies from chats, feeds, simulations, applications, and assessments, with full respect for the patient but with similar respect for the scholar and within the possible socioeconomic environment.

\section{Conflict of Interest Statement}

The authors reported no conflicts of interest.

The Journal policy requires editors and reviewers to disclose conflicts of interest and to decline handling or reviewing manuscripts for which they may have a conflict of interest. The editors and reviewers of this article have no conflicts of interest.

\section{References}

1. Pellegrini CA. Surgical education in the United States: navigating the white waters. Ann Surg. 2006;244:335-42.

2. Thoracic Surgery Directors Association (TSDA). TSDA cardiac surgery simulation curriculum. Available at: https://tsda.org/education/tsda-cardiac-surgerysimulation-curriculum/. Accessed May 6, 2020.

3. Brown TS, Norberg LJ. Balanced Scorecard Report: Building Executive Alignment, Buy-In, and Focus with the Balanced Scorecard SWOT. Boston, MA: Harvard Business School Publishing; 2001.

4. Kaplan RS, Norton DP. Linking the balanced scorecard to strategy. Calif Manag Rev. 1996;39:53-79. 
5. Edmondson AC, Winslow AB, Bohmer RM, Pisano GP. Learning how and learning what: effects of tacit and codified knowledge on performance improvement following technology adoption. Decis Sci. 2003;34:197-224.

6. Bradbury NA. Attention span during lectures: 8 seconds, 10 minutes, or more? Adv Physiol Educ. 2016;40:509-13.

7. Polanyi M. The Tacit Dimension. Chicago: University of Chicago Press; 1966.

8. Bruner JS, Goodnow JJ, Austin GA. A Study of Thinking. New York: Wiley; 1967.

9. Fann JI, Caffarelli AD, Georgette G, Howard SK, Gaba DM, Youngblood P, et al. Improvement in coronary anastomosis with cardiac surgery simulation. J Thorac Cardiovasc Surg. 2008;136:1486-91.
10. Papaspyros SC, Javangula KC, O'Regan DJ. Surgical training in the 48-h week: a novel simulation and educational tool. From amateur golfer to professional pilot. Eur J Cardiothorac Surg. 2009;36:511-5.

11. De Raet J, Arroyo J, Büchner S, Siregar S, Andreas M, Halvorsen F, et al. How to build your own coronary anastomosis simulator from scratch. Interact Cardiovasc Thorac Surg. 2013;16:772-6.

12. Schoemaker PJ. Multiple scenario development: its conceptual and behavioral foundation. Strateg Manag J. 1993;14:193-213.

13. De Raet JM, Desimone JP, Sergeant PT. Off-pump coronary artery bypass grafting: anno 2011. Multimed Man Cardiothorac Surg. 2011;2011:mmcts.2004 000539 . 